\title{
Apparent Threshold of Lead's Effect on Child Intelligence
}

\author{
Michael B. Rabinowitz ${ }^{1,2}$ Jung-Der Wang, ${ }^{2}$ and Wei-Tsuen Soong ${ }^{3}$ \\ ${ }^{1}$ Harvard Medical School, Boston, Massachusetts, USA; ${ }^{2}$ Departments of \\ Internal Medicine and Public Health, National Taiwan University, College of \\ Medicine and ${ }^{3}$ Department of Psychiatry, National Taiwan University, \\ College of Medicine, Taipei, Taiwan, Republic of China
}

The developing human brain is perhaps the most sensitive of the many targets of lead toxicity. This particular sensitivity is a driving factor in setting health and environmental standards for lead (US EPA, 1986). A recent compilation of studies of the association between lead and IQ has shown a consistent dose-response pattern across the range of reported exposures (Needleman and Gatsonis, 1990). In surveying the neurotoxicity of lead in humans and animals, there has been speculation of the existence of a threshold for these effects which may become apparent at lower lead levels (Davis et al 1990). In that context we examined our data of tooth lead and IQ scores to determine whether there was any apparent threshold for this effect. This cohort's lead levels are among the lowest documented and provide the opportunity to extend downward the range of interest.

Family factors are the strongest predictors of a child's intelligence, in particular the parent's intelligence (Bouchard and McGue, 1981). We therefore followed the model of Perino and Ernhart (1974) by examining whether at various levels of lead there is a disruption of the usual association between family and child intelligence. As noted by Bellinger and Needleman (1983), a difference in the correlations between parental and child intelligence in two groups, high and low lead, may be an artifact of other relationships among the predictor variables. Accordingly, they recommend a more appropriate test that would search for differences in the IQ deficits according to lead level, where the IQ deficit is the difference between a child's observed $I Q$ and the $I Q$ predicted from alI available information about the child aside from lead.This is especially appropriate when the lead

Send reprint request to M. B. Rabinowitz, Marine Biological Laboratory, Woods Hole, Massachusetts 02543. 
exposure correlates with the family's educational background. We examined our data this way.

\section{MATERIALS AND METHODS}

Children were recruited into the study by virtue of their attending grades one through three in one of seven elementary schools in Taiwan, the Republic of China, which were chosen because they represented a wide range of potential lead exposures and served populations with broadly similar ethnic compositions.

Two schools were near lead smelters, one was in a rural village, and four were in Taipei City. Together they contain 123 classrooms in grades 1,2 and 3 , serving about 4600 pupils. The average age of the first grade children was 6.7 years (std dev $=0.4$ ).

From October 1989 to January 1990 we collected teeth and asked the teachers to complete a small form to identify the child, when the tooth was shed, and location of the tooth in the mouth. At least one tooth was recieved from 764 children. A total of 940 teeth were collected, but 78 were judged to be too decayed or small to analyze.

The tooth lead levels were determined following the earlier method used in Boston ( Rabinowitz et al 1989). Two portions of post-natal dentin were sampled from between the pulp cavity and the neo-natal line. The lead was determined by anodic stripping voltammetry (ESA, model 3010A, Bedford MA). The standard deviation of the proceedural blank, which is a useful estimate of a portion of the uncertainty of the method was $3.4 \mathrm{ng}$, representing about $6 \%$ of the lead present in an average sample. Also, a standard solution of lead-enriched calcium chloride was prepared and its lead content was determined by professor William Manton of the University of Texas using isotope dilution mass spectrometry. It was then measured along with each batch of teeth and was found to contain 51.8 (std dev= 3.4) ng, not different from the value of 52.3 (std dev $=0.4$ ) ng by the absolute reference method.

An additional estimate of our laboratory's quality control is our participation in the Centers for Disease Control blood lead proficiency testing program. During the months when we were measuring teeth, we also measured 24 samples of blood which ranged from 3 to 84 ug/dl. The average absolute difference between our value and the target value was $2.5 \mathrm{ug} / \mathrm{dl}$ (std dev 1.8).

The reliability of this method can be assessed by comparing several incisors from the same child. 
Considering the 68 children who gave only two incisors, the spearman correlation coefficient of the two lead concentrations was 0.77 , with a median difference between the two incisors of $1.1 \mathrm{ug} / \mathrm{g}$.

After tooth collections were completed, the teachers of the 764 children who submitted a tooth were given a one page, 51 item forced choice questionnaire about the child's classroom behavior, including their IQ test result. For the schools within Taipei county the Raven's Colored Progressive Matrices (CPM) test is routinely administered during the second through fourth month of school during the first grade. The scores for this IQ test are the number of correct answers, typically ranging from 2 to 36 . Over 97 of the teacher forms were completed and returned, a remarkedly high rate.

Also, a two page questionnaire for the parents to complete about their age, education, employment, family composition, moving, language usage, pregnancy events, maternal smoking and drinking habits, delivery, and maternal and child health, a total of 40 variables. The response rate from the parents was somewhat lower, averaging $90 \%$. Parental education was scored into seven categories: none (self-taught), any primary, any middle, any high, any vocational, any college, or any graduate school attendance. Employment responses were categorized into 9 groups: technical or professional, administrative, supervisory, sales, service, farming, fishing, semi-skilled, unskilled, or at home.

With 685 parent and 740 teacher questionnaires 1589 with CPM test scores) available, only 465 cases had an incisor lead value and an IQ score. Because of the uncertainty of directly comparing incisors with molar or canine teeth (Rabinowitz et al 1991), their having different mean lead levels and periods of growth, only incisors ( $71 \%$ of the teeth) were considered. Also, a few cases were excluded because of an unusual factor which would place the child at an extremely high risk of a learning disorder. These included having cerebral palsy, meningitis, birth weight less than 2000 grams or having ever been hospitalized for more than 10 nights on one occasion, not including child birth (Table 1 ). Taken together these criteria reduce the number of subjects by 22 (11 of each gender) yielding 443 cases. There was no tendency for the excluded cases to be over- representative of extremely high or low incisor lead levels or to be from schools near a smelter or in Taipei City. For the regression model of CPM test scores, information about handedness and parental education are required. This further reduced the number of cases with sufficient information to 380 . 
Table 1. Average level ( \pm 1 S.D.) of tooth lead and CPM test scores of children excluded from our analysis.

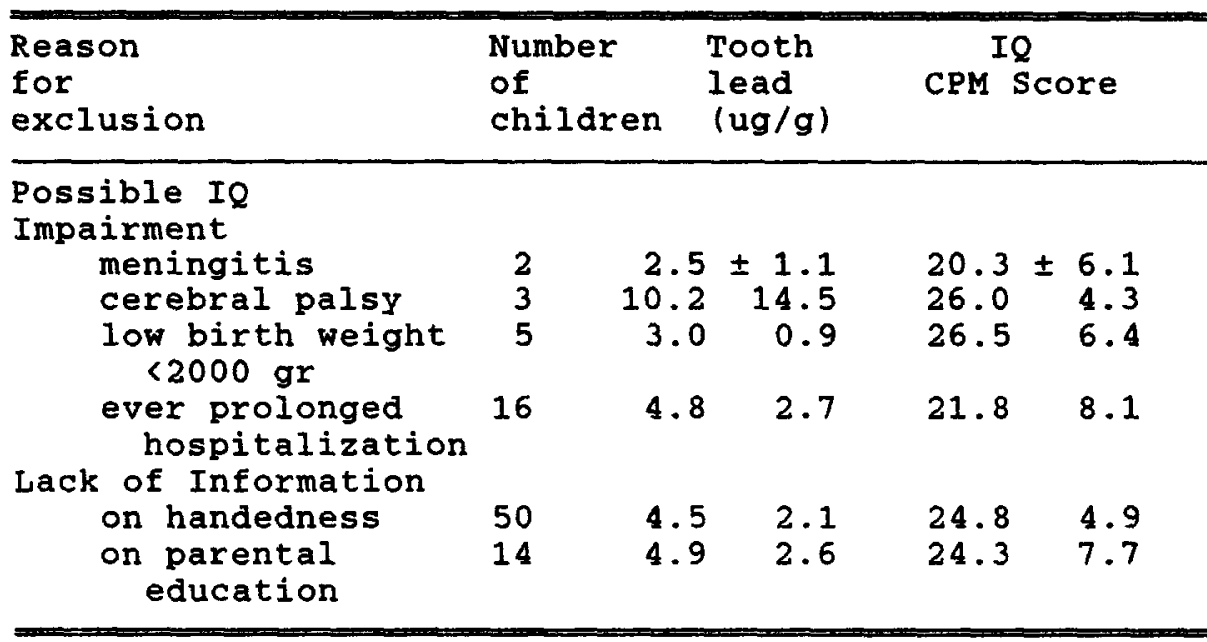

\section{RESULTS AND DISCUSSION}

We explored the relationship between the child's IQ and its predictors at various lead levels. The IQ measure was the test result from the CPM test, which averaged 25 ( std dev $=5.7$ ). In this population of the 40 variables measured for each child, the only ones realated to IQ at $p<0.15$ are gender, birth order, school grade, mothers and fathers occupation and education, handedness, history of seizures, and recent change in address.

Direct IQ data from the parents was unavailable, but we used parental education as a surrogate measure. This was practical because in Taiwan, educational opportunities are readily available and advancement is limited by the applicants performance in open examinations. Therefore, we used a composite variable, parental education, which is simply the average of available maternal and paternal education data. This new variable correlates well with the child's IQ, $r=$ .41 .

We constructed the best parsimonious multiple regression model of IQ (CPM Score), without a lead term ( $r$-squared 21 percent, $F=25.5, p<.0001)$. The parental education variable was the most potent predictor of the child's test score and alone accounted for 17 percent of the variance in the child's IQ. Our model was: The Predicted score $=18.6+0.84 *$ Gender $(1$ or 2$)+$ $1.7 *$ Parental Education $(1$ to 7$)-1.7 *$ Ambidextrous 10 or 1$)-1.2 *$ Grade $(1$ to 3$)$. This provided a predicted score for each child which was subtracted from their 
actual test results to obtain an intelligence deficit, which might be attributable to lead (Bellinger and Needleman 1983). This deficit averaged zero ( std dev 5.1, normality 0.98 , skewness 0.25 ) and ranged from13.3 to 15.5. The correlation between lead and this deficit is weak (Pearson $r=0.094, n=380, p=.06$ ).

Table 2 shows the association between incisor lead levels and the calculated CPM score deficit. Since we were interested in detecting any threshold of lead's effect, we tried various limits and compared the mean deficits above and below each trial limit using the non-parametric Mann-Whitney test. The lowest lead level across which there is a difference would be the threshold of lead's effect. There was no difference in mean deficits for children below or above the lower trial limits, such as 2 or $3 \mathrm{ug} / \mathrm{g}$. Any threshold must be at higher lead levels. However, the mean deficit of children above $3.5 \mathrm{ug} / \mathrm{g}$ was statistically greater than those below $3.5 \mathrm{ug} / \mathrm{g}$. The reason the $\mathrm{z}$ value changes abruptly when lead levels at or above $3.5 \mathrm{ug} / \mathrm{g}$ are considered is because of the large number of children in this population who show some apparent IQ deficits at these modest lead levels. Similarly when even higher lead levels are chosen as test thresholds, 4 or $6 \mathrm{ug} / \mathrm{g}$, for example, the difference in IQ deficits is still significant. This sets an upper bound on the threshold near or below $3.5 \mathrm{ug} / \mathrm{g}$.

Figure 1 shows the distributions of CPM score deficits for children above or below $3.5 \mathrm{ug} / \mathrm{g}$. This is one example of the trial splits shown in Table 2 . Althought there is considerable overlap, the two lead groups display different degrees of IQ deficits. The higher lead children are 1.3 times more likely to have a deficit of more than 2 CPM units, 38 versus 29 percent, for example.

Another method to establish a threshold is to look for inflection points in the dose-response curve (segmental line analysis) (Piomelli et al 1982). This data shows no change in the slope (or interecpt) of the lines across any trial threshold.

The usual measure of lead exposure is blood lead concentration. Tooth lead levels of shed incisors from Boston correlate well with blood lead at 57 months of age, $r=.56$ among 88 children (Rabinowitz et al 1989). Using that calibration line, a tooth lead of $3.25 \mathrm{ug} / \mathrm{g}$ corresponds to a blood lead of approximately $8(+/-2)$ ug/dl, below the currently accepted safe level of blood lead. (Centers for Disease Control, 1985). 


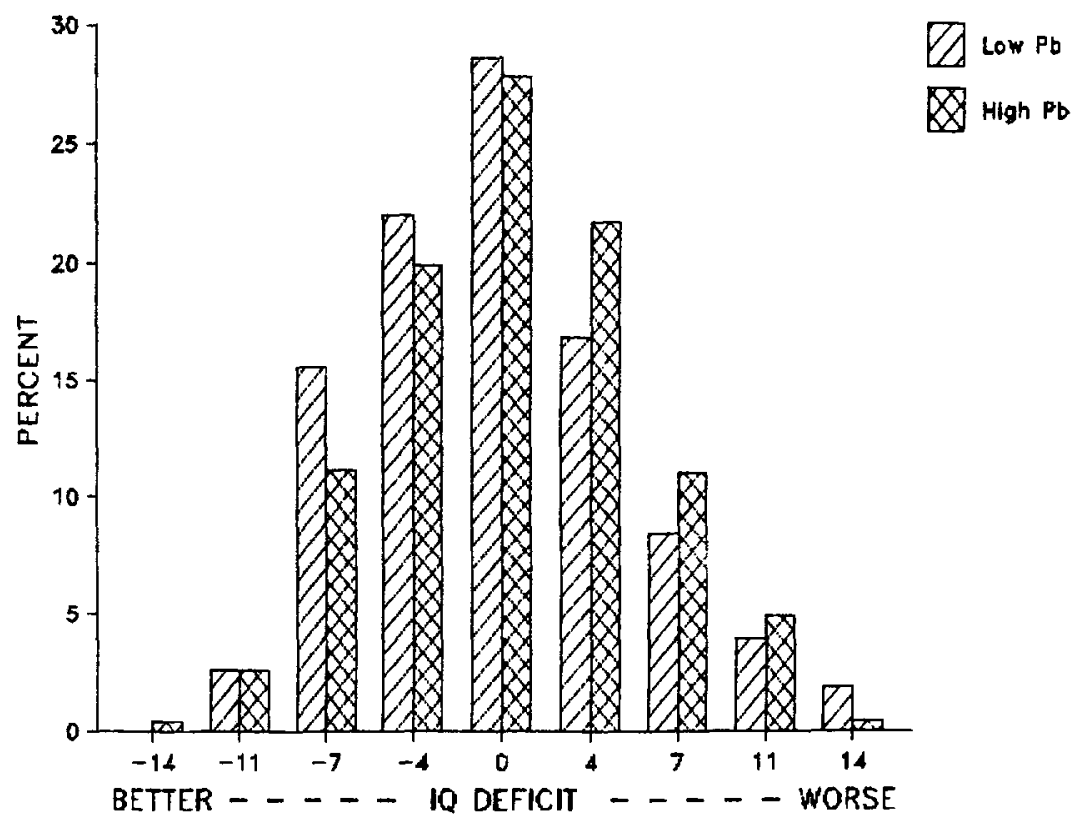

Figure 1. The distributions of intelligence deficits for children with incisor lead levels above or below $3.5 \mathrm{ug} / \mathrm{g}$. The deficit is the difference between the actual score on the Colored Progressive Matrices Test and the predicted score based on a four term regression model.

Table 2. Intelligence deficits among children categorized by their incisor lead level.

\begin{tabular}{|c|c|c|c|c|c|c|c|}
\hline \multirow{2}{*}{\multicolumn{2}{|c|}{$\begin{array}{l}\text { Tooth \# } \\
\text { Lead } \\
\text { Category }\end{array}$}} & \multirow{3}{*}{$\begin{array}{r}N \\
27 \\
353\end{array}$} & \multicolumn{2}{|c|}{$\begin{array}{l}\text { CPM } \\
\text { Deficit }\end{array}$} & \multirow{3}{*}{$\begin{array}{l}\begin{array}{l}\text { CPM } \\
\text { Score } \\
\text { Median }\end{array} \\
28 \\
25\end{array}$} & \multicolumn{2}{|c|}{$\begin{array}{l}\text { Mann-Whitney } \\
\text { Test }\end{array}$} \\
\hline & & & Mean & $S D$ & & $\mathbf{z}$ & $\mathbf{p}$ \\
\hline $\begin{array}{l}< \\
>=\end{array}$ & $\begin{array}{l}2 \\
2\end{array}$ & & $\begin{array}{r}-0.8 \\
.1\end{array}$ & $\begin{array}{l}6.0 \\
5.0\end{array}$ & & 1.0 & 0.3 \\
\hline $\begin{array}{l}< \\
>=\end{array}$ & $\begin{array}{l}3 \\
3\end{array}$ & $\begin{array}{r}95 \\
285\end{array}$ & $\begin{array}{r}-0.3 \\
.2\end{array}$ & $\begin{array}{l}5.7 \\
4.7\end{array}$ & $\begin{array}{l}27 \\
25\end{array}$ & 1.3 & .2 \\
\hline$>=$ & $\begin{array}{l}3.5 \\
3.5\end{array}$ & $\begin{array}{l}155 \\
225\end{array}$ & $\begin{array}{r}-0.3 \\
.3\end{array}$ & $\begin{array}{l}5.1 \\
5.0\end{array}$ & $\begin{array}{l}27 \\
25\end{array}$ & 29.6 & .0000 \\
\hline $\begin{array}{l}c \\
>=\end{array}$ & $\begin{array}{l}4 \\
4\end{array}$ & $\begin{array}{l}198 \\
182\end{array}$ & $\begin{array}{r}0.0 \\
.1\end{array}$ & $\begin{array}{l}5.2 \\
5.0\end{array}$ & $\begin{array}{l}27 \\
25\end{array}$ & 60.8 & .0000 \\
\hline $\begin{array}{l}< \\
>=\end{array}$ & $\begin{array}{l}6 \\
6\end{array}$ & $\begin{array}{r}304 \\
76\end{array}$ & $\begin{array}{r}-0.8 \\
.1\end{array}$ & $\begin{array}{l}6.0 \\
5.5\end{array}$ & $\begin{array}{l}26 \\
23\end{array}$ & 37.1 & .0000 \\
\hline
\end{tabular}

\# The 380 children were split at various lead levels to search for a threshold above which deficits would be different from below that lead level. The Mann-Whitney test was used to compare the two groups. There is an apparent threshold between 3 and $3.5 \mathrm{ug} / \mathrm{g}$. 
Any threshold near 3 or $4 \mathrm{ug} / \mathrm{g}$ appears not to be abrupt nor decisive. The difference in mean deficits across any of the calculated thresholds is small. This difference becomes statistically significant (not attributable to chance) by virtue of the large numbers. Although the effect size at these concentrations is modest, when extrapolated to populations of millions of children the cummulative effect on a society is not trivial. The intelligence measure in this study, the test score on the Colored Progessive Matrices Test, is particularly culture and language free, and it correlates well with the more common, 100 centered, Wechsler Scale (Sattler, 1974). A drop of 1 unit on the CPM scale is equivalent to 2 or 3 Wechsler IQ points. In Taiwan the middle fifty percent fall between CPM scores of 20 and 28 or IQs of about 90 and 112 .

This population is generally well nourished, and anemia among elementary school children is $3 \%$ according to a stratified random sample (Kao et al, 1990). Therefore it is not expected to be particularly sensitive to lead. However, before these conclusions could be confidently applied to other groups, replication would be warranted.

Acknowledgments. This research was funded by a grant from the National science Council of the Republic of China (NSC 79-0421-B002-1Z). Excellent technical support was provided by Wen-ying Chao, Chin-siung Lu, and Dr. Kun-yu Chao. statistical advice was kindly provided by Chen-hsin Chen. This work could not be possible without the full support of the parents, school principals, classroom teachers and the children themselves. We are very thankful for their enthusiastic support.

\section{REFERENCES}

Bellinger D, Needleman $H$ (1983) Lead and the relationship between maternal and child intelligence. J Pediat 102:523-527 and 103:830-832

Bouchard T, McGue M (1981) Familial studies of intelligence. Science 212:1055-1059

centers for Disease Control (1985) Preventing Lead Poisoning in Young Children. Atlanta, United States Department of Health and Human Services; no. 99-2230

Davis, J (1990) Risk assessment of the developmental neurotoxicity of lead. Neurotoxicol 11285-91

Kao MD, Huang HJ, Tzeng MS, Lee NY, Shieh MJ (1990) The Nutritional status in Taiwan- Anthropometric Measurment. Taipei: Fu-Jen University, Department of Food and Nutrition science 
Needleman H, Gatsonis C (1990) Low-level lead exposure and the IQ of children. J Amer Med Assoc 263:673-8

Perino J, Ernhart C (1974) The relation of subclinical lead level to cognitive and sensorimotor impairment in black preschoolers. J Learn Disabil $7: 616-620$

Piomelli S, Seaman S, Zullow D, Curran A, Davidow B (1982) Threshold for lead damage to heme synthesis in urban children. Proc Natl Acad Sci 79:3335-9

Rabinowitz M, Bellinger D, Leviton, A (1989) The Blood lead - tooth lead relationship among Boston children. Bull Environ Contam Toxicol 43:485 - 492

Rabinowitz M, Bellinger D, Leviton A, Wang JD (1991) Lead levels among various deciduous tooth types.

Bull Environ Contamin Toxicol 47:602-608

Sattler,J.(1974) Assessment of Children's Intelligence, pp. 44,82, and 155. Saunders, Philadelphia

United States Environmental Protection Agency,

Environmental Criteria and Assessment office (1986)

Air Quality Criteria for Lead. EPA 600/8-83/028cF

Received March 5, 1991; accepted November 30, 1991. 